\title{
The Influencing Factors of Consumer Online Shopping and Improvement of Quality of Service of Network Group Shopping Website
}

\author{
He Daizhong, Gao Dingli \\ Chengdu Normal University, Chengdu, Sichuan, China,610041
}

\begin{abstract}
The rise of network group shopping in 2010 has made a vigorous development trend, which not only achieved good marketing performance, but also changed people's consumption patterns. This paper studies the influencing factors of consumers' network group shopping and the effective strategies to improve the service quality of group shopping websites based on the factors that affect the network group shopping. Key words: network group shopping; network group shopping website; service quality; promotion strategy

Network group shopping as a popular online transaction in China is a new type of consumption, in 2010 it began to rise. In recent years it began to show an "explosive" growth, and there are a large number of audience to buy as well as the growing coverage of goods. Network group shoppingin the results obtained in the modern marketing is of great research value, which contains a variety of factors is worth pondering and research. As the name suggests, "network group shopping" has two basic elements of the term: one is the network, the other is group shopping. Before fulfillment of the network group shopping, the phenomenon of group shopping already exists. In the 1980s, some companies or individuals through large quantities of orders to the supplier to obtain lowerprice than the market price of products or services [1], so this phenomenon is more common. For consumers or buyers, the benefits of the price and service optimization are a major motivation to promote a group shopping; while for sellers, the bulk sales brought about by the rapid turnover is another factor to promote the shopping. With the popularity of Internet applications and the expansion of the scale of Internet users, insisting on price advantage and service
\end{abstract}


optimization, based on the network, group shopping has a new opportunity cause its advantage of new sale method, short business cycle and fast profit time.

\section{The advantages of network group shopping}

Network group shopping refers to a certain number of consumers through the Internet channel group, with a lower discount to buy the same commodity business activities [2]. Network group shopping began from Groupon group shopping site in the United States in 2008, and its high sales, tremendous profit will be physical retailers and network consumers in close contact with the network marketing strategy to bring rapid profits at the same time [3] But also attracted more power to imitate business copy, the success of China's Meituan web online is an example. Network group shopping is a modern technology platform based on network marketing, but it is different from the traditional B2C, $\mathrm{C} 2 \mathrm{C}$ e-commerce, that is, consumers and businesseshave a group shopping site as a intermediaries for buying and selling sides, and through the group shopping site intermediary role to achieve commodity buying behavior. Among them, the group shopping site intermediary value mainly for three aspects: first one is to establish a certain relationship with the business, through negotiations with the merchant to locate commodity prices and display commodity information; the second one is to organize a number of consumers with the same intention to buy, and to reach a commodity shopping agreement, in order to achieve the two sides on the ideal price and sales aspirations; third one is safe and reliable implementation of the sale process, which will reach the transaction successfully.

Based on the intermediary roleof group shopping site, network group shopping on a more secure, reliable basis further shows its unique advantages. First of all, the price of group shopping is equivalent to the wholesale price in the real world. So that consumers can take to buy affordable, and high quality goods. Second, businesses can also take this to achieve the sale of bulk commodities to speed up the operating speed and cash flow. Third, through the platform of group shopping, it willunite consumers who have the same commodity willing and make the group bargaining, which not only reduce the cost of sales, and better achieve the buyer's market changes, so that consumers can enjoy a more personalized high quality sales services. Fourth, if the networkgroup shopping goods quality problems take place, they can also be resolved through collective rights protection. Due to the large number of defenders, when the quality of arbitration related institutions, it is able to ensure fairness and impartiality.

\section{The factors affecting consumer network group shopping}

Whether consumers buy a commodity depends on many factors, one of the psychological factors that can not be ignored is a major leading factor. Although the quality of goods, seller service attitude are very important, the consumer's 
psychological perception and emotional acceptance can produce impulse to buy, so the business through a variety of psychological warfare promotion is also very normal. But psychological warfare does not mean cheating and fraud, once seen through the consumer, the seller's loss is not just economic. Therefore, the quality of goods and commodity prices are the most basic factors that will increase sales, but also affect consumers to join the network buy the main factors. It has been found that the price sensitivities of consumers in the network environment are higher than those in the traditional channels [4], although some consumers may have more information about the higher prices of the same type of goods, but for most consumers, the advantage of low prices has the relationship with the credibility of group shopping site. When the group shopping site launched a commodity and marked the original price, discount rate and other information, the consumer's attention will be attracted to buy; and when the groupshopping site announced the number of participants and the remaining time, the consumer shopping Will be very strong, the mechanism is: buy, the size of the number of participants and group activities such as the remaining time of the dynamic changes in information will enhance consumer confidence in the quality of the goods, low prices and excellent quality of the effective integration is bound to promote the consumer shopping behavior. Therefore, no matter what kind of promotional activities, commodity quality and commodity price factors are definitely the most important factors affecting sales, especially for network group shopping .

As online shopping consumers, the establishment of the trust of network goods and services is not easy, because the online shopping and traditional physical store shopping situation and experience are different, the virtual network will allow consumers to have more doubt. Of course, with the maturity of the electricity business and the development of network consumption and the growing size of users, this initial sense of doubts has been slowly disappearing, and formed the convenient, fast, affordable and personalized consumption habits in network sales. This does not rule out some of the seller's fraud and misrepresentation of goods, but most of the sales website and the seller's reputation are good, which for individual consumers in terms of a positive impact on their consumer psychology factors. Therefore, the tendency of trust can make the trustee in the face of unfamiliar things to be adjusted by the tendency to trust [5]. In network group shopping, because of the large number of consumers, this trust is particularly important, so each consumer's personal information can be combined to form a collective member of the online shopping group trust. Significantly, even if there are a small number of members who have suspect about group shopping, then in the driven of other people, few people will give up their suspicion. It can be seen that the method of network group shopping to some extent in the use of the role of "group", including the number of participants can further strengthen the herd mentality. Asch has shown through research that a third of the participants are influenced by group opinions, making decisions that accept group opinions, even if the group's opinion is not necessarily correct [6]. Thus, this group influence will result in a lot of people's herd mentality, and 
change their ideas. Group shopping and the size of the number of shoppings to promote the internal mechanism is the case.

As mentioned above, the three components of sales around the network shopping are network sellers (including service sites), goods and consumers, then as the entire sales process, the most critical and decisive role is network sellers (including the service website) itself; especially in the network shopping such a large scale activities in the commodity type has been fixed under the premise of the business and how the site will determine the consumer network to buy the most important factor. For the seller, the so called "sale is not one" is the truth. Then in order for the transaction to become a reality, businesses and consumers must at one point to achieve the interests of consistency, so that the inherent contradiction between each other to zero, which requires the quality of goods is guaranteed, at least in consistency with described information; in the united price with consumer satisfaction, the seller's profits are guaranteed. Therefore, to honest business and consumer trust is still the first to follow the business. Moreover, the site, it is the whole process of trading before and after the operation of the strategy and it is essential, on the one hand it is through the website to promote commodity information, to promote the meaning of group shopping, recruiting the number of participants. On the other hand, the transaction process must provide safe and reliable, so consumers are satisfied with the quality of services, of which the safety of consumers to measure the value of online shopping site worthy of trust is not one of the many factors, because of its direct relationship between the interests of consumers money gains and losses, will become the impact ofthe most direct and most sensitive factors of consumer participation in the network shopping.

\section{To improve network service quality of the strategy}

Although the merchant, the merchandise and the consumer are the main constituent elements of the network sale, the transaction realization process mustoperate by the group shopping website, including the commodity information presentation, the group shopping operation strategy, realize the payment shipment, the customer rights protection feedback and so on. In fact, in this new business model of the network shopping, the shopping site is always a promoter, operators, implementors, service providers, the role of profit, because of their business and the basis of cooperation and the interests of convergence, it is easy to stand on the side of the seller, and become the opposite of the interests of consumers, this is the situation which site must be avoided. Therefore, the shopping site should do something to avoid this happening, it becomes the key to the operation of group shopping. In fact, the problem is mainly focused on the maintenance of consumer rightsto improve the safety and reliability of buy site, because this is a fundamental premise. First of all, security, consumer interests are mainly concentrated in the quality of goods, the price honesty and payment security. $t$ is clear that the group shopping site to ensure that consumers of financial loss. Followed by the reliability, refers to the group shopping activities 
to be transparent,that is the site information to be true and complete, and the activities of the processnot existing hidden consumption or fraud. In short to improve the integrity of the site to make a fuss, make efforts to promote the network to buy the scale of double harvest. Customers shopping site security is mainly reflected in the customer to pay and confirm the receipt. The shopping site must give consumers a guarantee mechanism and service commitment to minimize the concerns of consumers involved in shopping, so that group shopping activities can implement effectively.

It is concluded that 6 of the 10 key factors that have the greatest influence on the shopping decisions of the network consumers are business service factors and 4 belong to the commodity information factors [7]. The commodity information is one of the contents of the business service to the customers, and commodity information factor in the final analysis is also a part of service factors. It can be seen that the quality of service for both buyers and sellers are very important, not just for the consumer's one way behavior. High quality services refers to the whole process of business transactions around the needs of consumers to make a variety of good activities, such as businesses to provide consumers with accurate product information, reliable service information, secure payment methods to safeguard the rights and interests of the channel, interactive exchange window, a variety of promotions, product returns and refunds and other refunds. For network shopping sales, these premium services must be provided by the group shopping site. If consumers do consider that the group shopping site service attitude is good, the quality of service is high, it will form a good shopping pleasure and more positive consumer sentiment, thus enhancing the network shopping trust judgment. In addition, the group shopping the site's personalized service is also conducive to improving consumer satisfaction and customer viscosity, and even help to establish a more stable old customer relationships. Personalized services for consumers of different personality needs, both on the goods, but also on the price, as well as transactions on the way, in short, it is based on customer needs to provide products and services to make online shopping more attractive to different types of consumers to join.

With the intensification of competition in the network sales, the e-business customers are particularly concerned about the evaluation of the sale, which is to improve business reputation, to enhance business sentiment, to promote business sales. Some businesses therefore spend money to buy a brush, in fact, the effect is limited, so a negative feedback may be offset several times. Business needs praise can be understood, but the praise should come from the consumer, because if consumers do not buy it, business sales will fail, or that there is no more long term prosperity. Consumer evaluation is good or bad depends on their perception of business confidence to some extent. Perceived trust and consumer perceived cost of network shopping, perceived value and perceived risk. First, consumers perceive the lower the cost of goods, the easier it is to buy, that is to say, the network to buy a large number of sales to achieve profits do not reduce the practice is justified. Second, consumers perceived value of the network to buy the higher the more easily group. Perceived value is perceived by consumers and their products or services to obtain the cost of trade off after the trade off of the 
effectiveness of the product or service evaluation, which increased perceived value will increase his perceived trust in buy. Third, perceived risk has the most direct influence on consumers' shopping. When consumers feel that network shopping is very safe and reliable, their perceived trust in group shopping will be maximized. In short, as long as consumers have enough sense of trust, he will give business evaluation of praise, which is the effect of network shopping.

As to improve the quality of network buy site, we must strengthen the site of self-discipline and regulation. To continue to establish and improve laws and regulations, through standardized management standards to ensure that the site has a standard self-management, but also to ensure the quality of web site service quality supervision basis. As e-commerce in technology content, information dissemination speed on the absolute advantage, has on the existing market structure has a huge impact [8]; and with e-commerce in another wonderful network buy expansion of development, many shopping sites to establish and join the ranks of the network to buy corps, such as Jingdong Mall, Taobao, leading to network marketing more intense competition and intense market. In this case, buy site and its network of goods and sales of services must protect the quality and adoption of a variety of marketing strategies to motivate consumers to buy behavior.

\section{References:}

[1] [6] Xu Zhifen. Network Shopping in the Impact of Consumer Behavior Factors [J]. Modern Marketing .2013,11: 62

[2] Jiang Ling. China's Shopping Site Quality of Service Problems and Countermeasures [J]. Enterprise Technology Development .2012,01: 23-25

[3] Zhong Kai. Impact of Consumer Groups to Buy the Psychological Factors of Motivation [http]. Http://www.docin.com/2013,01

[4] [5] Huang Ping. Network Buy Consumer Trust Factors in the Literature Review [J]. World wisdom .2011,10: 230

[7] He Yunchun. An Empirical Study on the Factors Influencing Consumers' Purchase Intention in Network Group Purchase [J] Value of Engineering.2015,17: 63-67

[8] Zhu Juan.E-commerce Background of the Retail Business Model of Change Analysis [J]. Business Economics Research .2015,05: 45-47 